\title{
Standardized ileal digestibility of amino acids in some cereals, rapeseed products and maize DDGS for broiler chickens at the age of 14 days* $^{*}$
}

\author{
W. Szczurek ${ }^{1}$ \\ National Research Institute of Animal Production, \\ Department of Animal Nutrition and Feed Science \\ 32-083 Balice, Poland
}

(Received 30 November 2009; revised version 12 January 2010; accepted 29 January 2010)

\begin{abstract}
The experiment was conducted to assess the ileal digestibility values for the purpose of evaluating the ability of 14-day-old broilers to utilize the amino acids (AA) from different plant feeds. The feeds included two cereals: maize and wheat; full-fat seeds of rape (FRS); four local by-product: cold-pressed rapeseed cake $(\mathrm{RC} 1)$, rapeseed cake from precooked $\left(90^{\circ} \mathrm{C}\right)$ seeds $(\mathrm{RC} 2)$, solvent-extracted rapeseed meal (RSM), maize distillers dried grains with solubles (DDGS), and soyabean meal (SBM), used as the model protein feed. The standardized ileal digestibilities of AA (SID) were measured using the assay diets containing $\mathrm{Cr}_{2} \mathrm{O}_{3}$ as an indigestible marker. A protein-free diet was formulated to estimate the basal ileal endogenous AA losses. Dietary protein in the assay diets was supplied solely by the test ingredients. Each diet was offered for 5 days to 4 replicate cages of 12 birds. For wheat the SID coefficients of most AA were significantly or numerically greater compared with maize. The numerical superiority of the SBM over all the other protein sources tested was found for SID of most AA, with statistically confirmed differences for threonine, tryptophan, serine and tyrosine. Among protein feeds examined DDGS had the lowest digestibility of lysine, methionine, threonine, tryptophan and cystine. Of the four rapeseed feeds, RSM had the lowest digestibility of lysine, histidine, alanine, glycine and serine. Considering the SID of the 18 amino acids, protein-rich feeds tested in this study were ranked as follows: SBM $>\mathrm{RC} 1>\mathrm{RC} 2>$ FRS $>$ RSM $>$ DDGS. However, the SID values of lysine and methionine in both rapeseed cakes ( $\mathrm{RC} 1$ and $\mathrm{RC} 2$ ) were comparable to those obtained for SBM.
\end{abstract}

KEY WORDS: chickens, ileal digestibility, amino acids, cereals, rapeseed products, maize DDGS

\footnotetext{
* Supported by the Ministry of Science and Higher Education, Project No. N N311 168533

${ }^{1}$ Corresponding author: e-mail: witen@poczta.onet.pl
} 


\section{INTRODUCTION}

Knowledge of the amino acid (AA) digestibilities of feed ingredients is important if broilers are to be fed with properly balanced compound diets. The use of digestible AA concept in diet formulation also allows to increase the dietary levels of alternate or low quality protein sources, which may be conducive to the diversification of poultry feeds market. There is now a considerable body of evidence demonstrating that the ileal digesta sampling is a more exact method of estimating the AA digestibility in chickens than the measurement of total AA flow via the excreta, including the use of the precision-fed rooster technique (Kadim et al., 2002; Lemme et al., 2004; Garcia et al., 2007). The great advantage of this approach is that chickens of different age classes can be used. It is increasingly recognized that in birds, the digestibility of AA increases with age (Adedokun et al., 2008). Huang et al. (2005) reported that, for some AA in maize, soyabean and canola meals, and ccreal by-products, digestibility coefficients determined by ileal sampling method using market-age broilers are not applicable for feed formulations for 14-day-old chickens. To date, however, reliable tabular ileal digestibility values for AA in common feed ingredients are still limited to the data determined with 6-week-old broilers (Lemme et al., 2004; Ravindran et al., 2005). A growing consensus also exists about the need to correct (standardize) the apparent digestibility for endogenous losses of AA (Lemme et al., 2004). Recent evidence suggests that the use of age-appropriate endogenous AA flows is necessary for obtaining accurate standardized AA digestibility values in birds at both very early and later ages (Adedokun et al., 2007).

The present paper reports on part of an ongoing study that has been carried out in our laboratory with the purpose of testing locally-grown crops and byproduct ingredients for ileal digestibility of their AA in young broiler chickens. Apparent digestibility coefficients of AA for two cereal grains, rape seeds and five plant-based co-products determined with 14-day-old chickens were standardized using age-specific endogenous AA losses assessed with the traditional proteinfree diet method. Comparative analysis of the standardized data for individual AA is presented separately for cereals and for plant protein sources, i.e. ingredients of medium to high protein content.

\section{MATERIAL AND METHODS}

The evaluated feed ingredients included maize, wheat and native seeds of winter Brassica napus rape (FRS); three by-products from processing of rapeseed for oil production: cold-pressed expeller cake ( $\mathrm{RC} 1)$, with the rise 
in temperature during pressing to $50-55^{\circ} \mathrm{C}$; expeller cake ( $\mathrm{RC} 2$ ), obtained as a residue after oil pressing at $90^{\circ} \mathrm{C}$ from flaked and mildly cooked seeds; rapeseed meal (RSM), produced by prepress-solvent extraction technology with desolventizing-toasting as a final stage of meal processing; maize distillers dried grains with solubles (DDGS) with moderately dark colour in visual evaluation; and a sample of soyabean meal (SBM) used as the model protein ingredient (Table 1). Test feeds served as the sole sources of crude protein (CP) in the

Tablc 1. Dry matter $(\mathrm{g} / \mathrm{kg})$, crude protein $(\mathrm{g} / \mathrm{kg} \mathrm{DM})$ and amino acid $(\mathrm{g} / 16 \mathrm{~g} \mathrm{~N})$ contents of the raw fecds cvaluated in the study

\begin{tabular}{lcccccccc}
\hline \multirow{2}{*}{ Item } & \multicolumn{7}{c}{ Fecd ingredicnt $^{1}$} \\
\cline { 2 - 9 } & maizc & wheat & FRS & RC1 ${ }^{2}$ & RC2 $^{2}$ & RSM $^{2}$ & DDGS & SBM \\
\hline Dry matter & 860.8 & 869.4 & 935.5 & 915.4 & 899.8 & 890.7 & 934.3 & 883.2 \\
Crude protein & 107.0 & 133.2 & 195.1 & 328.2 & 364.5 & 396.0 & 302.8 & 530.8
\end{tabular}

$(\mathrm{N} \times 6.25)$

\begin{tabular}{lrrrrrrrr} 
Amino acid & & & & & & & \\
Arg & 3.91 & 3.67 & 5.68 & 5.70 & 6.33 & 5.71 & 3.40 & 7.17 \\
His & 2.82 & 2.14 & 2.87 & 2.99 & 3.13 & 2.93 & 3.25 & 2.60 \\
Ile & 3.26 & 2.97 & 3.70 & 3.80 & 4.01 & 3.84 & 3.52 & 4.42 \\
Leu & 12.42 & 6.18 & 6.71 & 6.95 & 7.47 & 7.07 & 12.34 & 7.60 \\
Lys & 2.75 & 2.56 & 6.08 & 6.27 & 6.34 & 5.42 & 2.63 & 6.17 \\
Met & 2.42 & 1.77 & 1.82 & 2.26 & 2.32 & 2.42 & 2.15 & 1.45 \\
Phe & 4.88 & 4.18 & 3.57 & 3.72 & 4.10 & 3.85 & 4.66 & 4.99 \\
Thr & 3.42 & 2.60 & 4.53 & 4.67 & 4.84 & 4.50 & 3.56 & 3.91 \\
Trp & 0.64 & 1.21 & 1.06 & 1.35 & 1.42 & 1.18 & 0.84 & 1.47 \\
Val & 4.30 & 3.76 & 4.76 & 4.95 & 5.15 & 4.89 & 4.37 & 4.43 \\
Ala & 7.33 & 3.20 & 4.08 & 4.28 & 4.27 & 4.30 & 6.69 & 4.20 \\
Asp & 6.93 & 4.84 & 6.89 & 7.39 & 7.91 & 7.29 & 5.79 & 10.90 \\
Cys & 1.93 & 1.96 & 2.04 & 2.17 & 2.15 & 2.20 & 1.49 & 1.27 \\
Glu & 17.89 & 26.23 & 14.71 & 15.72 & 17.56 & 16.40 & 13.29 & 17.02 \\
Gly & 3.58 & 3.65 & 4.96 & 5.16 & 4.77 & 5.07 & 3.32 & 4.05 \\
Pro & 8.15 & 8.88 & 5.39 & 5.53 & 5.67 & 5.76 & 7.73 & 4.61 \\
Ser & 4.32 & 3.99 & 4.04 & 4.08 & 4.35 & 4.03 & 4.27 & 4.84 \\
Tyr & 2.49 & 1.46 & 2.99 & 2.95 & 3.20 & 3.04 & 3.62 & 3.76 \\
\hline
\end{tabular}

TFRS - full-fat rape seeds, RC1 and RC2 - rapeseed cakes, RSM - rapeseed meal, DDGS - maize distillers dried grains with solubles, SBM - soyabean meal; ${ }^{2}$ refer to the text for the information on rapesecd by-product fecds

assay diets. In the case of cereals, diets were based on $940 \mathrm{~g}$ of test cereal $/ \mathrm{kg}$. Diets containing feeds of medium to high $\mathrm{CP}$ levels were formulated, where possible, to be isoenergetic (11.88 MJ ME/ $\mathrm{kg}$ ) and isonitrogenous $(200 \mathrm{~g} \mathrm{CP} / \mathrm{kg})$ by varying the amounts of maize starch, rapeseed oil, sucrose and purified cellulose. For fullfat rape seeds this was not possible. Chromic oxide was added as an indigestible marker at $0.5 \%$ of the diet. The composition of the protein free diet (PFD) was that given by Kadim et al. (2002).

Male and female Ross 308 broiler chickens (sex ratio 1:1) were raised in battery 
brooders and fed with commercial starter diet during the first 8 days posthatching. Water and artificial light was provided continuously. On day 9, 432 birds of uniform body weight $(194 \pm 7 \mathrm{~g})$ were selected and assigned to 36 wire cages $(6 \delta$ and 69 per cage). Four replicate cages were then randomly assigned to each diet. The assay diets, in mash form, were offered ad libitum for 5 days prior to digesta collection at 14 day of age. The chickens were euthanized by a lethal injection of sodium thiopentone and the contents of the lower half of the ileum were collected. The ileum was defined as the portion of the small intestine from the vitelline diverticulum to a point $20 \mathrm{~mm}$ proximal to the ileo-caecal junction. Feeding of the birds and the digesta sampling and processing were carried out using procedures adapted from Kadim and Moughan (1997) and Kluth et al. (2005). All animal care and experimental procedures were reviewed and approved by the Local Ethics Committee for Animal Experimentation.

Dry matter (DM) content of test feed, diet and lyophilized digesta samples was determined by oven drying at $103^{\circ} \mathrm{C}$ for $24 \mathrm{~h}$. Samples were analysed for total nitrogen using a Tecator Kjeltec Auto 1030 System. Chromium determinations were made using atomic absorption spectrophotometry according to Saha and Gilbreath (1991). Prior to AA analyses, the samples were hydrolysed in $6 \mathrm{~N}$ $\mathrm{HCl}$ at $110^{\circ} \mathrm{C}$ for $22 \mathrm{~h}$. For determination of Met and Cys, preliminary oxidation with performic acid was carried out. Tryptophan was assayed following alkaline hydrolysis of samples in $\mathrm{BaOH}$. Amino acid concentrations were determined by HPLC after postcolumn derivatization (AOAC, 2000; method 982.30 E). All analyses were performed in duplicate.

The ileal endogenous amino acid losses (IEAA) in birds fed the PFD diet were calculated using the formula proposed by Moughan et al. (1992). The apparent ileal digestibilities of AA were transformed to the standardized digestibility (SID) values with the formula given by Lemme et al. (2004). The SID data were subjected to one-way analysis of variance using the Statistica ver. 6 Software System (www.statsoft.com). Statistical significance of differences between means within each type of feed ingredients was assessed by the Tukey's HSD test. Level of significance was set at $\mathrm{P}<0.05$.

\section{RESULTS AND DISCUSSION}

The CP contents of the test cereals and by-products (Table 1) were within the range of published values (Perttilä et al., 2002; Smulikowska and Rutkowski, 2005; Pahm et al., 2009). Except for Trp, concentrations of indispensable AA (g/16 g N) in maize were somewhat greater compared with wheat. The proportions of Lys and Thr were highest in rapeseed cakes protein and lowest in DDGS protein. The 
relative contents of Met and Cys were higher in rapeseed feeds than in SBM. It is also noteworthy that the RSM protein contained considerably less Lys than nontoasted rapeseed cakes or full-fat rape seeds (Table 1). These analytical results are in good agreement with the data presented by many authors for oilseed meals, cereals and DDGS from maize-based ethanol production tested with chickens of different ages (Newkirk et al., 2003; Huang et al., 2005; Ravindran et al., 2005; Pahm et al., 2009).

The current study was designed to assess the ileal digestibility coefficients for the purpose of determining the ability of 14-day-old broilers to utilize the AA from evaluated feeds. In addition, the basal (inevitable) IEAA losses in chickens of the same age were estimated. Glutamic acid, Asp, Thr and Leu dominated the AA profile of endogenous protein in the ileal contents, whereas the concentrations of Met, Trp, Cys and His were the lowest (Table 2). Similar relations for these endogenous AA have been previously determined by the PFD method in chickens between 2 and 5 weeks of life (Ravindran et al., 2004; Adedokun et al., 2007; Szczurek, 2009). It is important to note, however, that in this experiment flow values for individual AA were markedly lower than those determined by Ravindran et al. (2004) and Szczurek (2009) with 35- and 30-day-old broilers (for example, Met flows: 65 vs 101 and $89 \mathrm{mg} / \mathrm{kg} \mathrm{DM}$ intake, respectively), and similar to the data obtained in the study of Adedokun et al. (2007) for birds at day 15. That may be an indication that the use of IEAA flows determined with birds of a particular age for the correction of the apparent AA digestibility estimates obtained for broilers of a different age can deteriorate the precision of the SID calculations.

The SID values of AA in the evaluated ingredients are presented in Table 2. For wheat the coefficients of most AA were significantly $(\mathrm{P}<0.05)$ or numerically greater compared with maize. The present results contrast with those of a previous study by Garcia et al. (2007), where the SID coefficients of AA for 7- and 21day-old broilers were shown to be lower in wheat than in maize. These authors, however, in correcting apparent digestibility for basal IEAA flows used the compiled values assessed by the method with the use of enzymatically hydrolysed casein (EHC) with broilers at different ages (Lemme et al., 2004). On the other hand, the current results for cereals concur with previous observations showing lower apparent ileal digestibilities of Thr, Ile, Val, Phe, Glu, Gly, Ser, Met, Cys and Tyr in maize relative to wheat when tested with 2- or 6-week-old chickens (Huang et al., 2005; Ravindran et al., 2005).

The numerical superiority of the SBM over all the other plant protein sources tested in this trial was observed for SID of most AA, with statistically confirmed differences for Thr, Trp, Ser and Tyr (Table 2). These findings are compatible with the standardized digestibility data reported in previous studies with growing chickens (Adedokun ct al., 2008; Szczurek, 2009). 


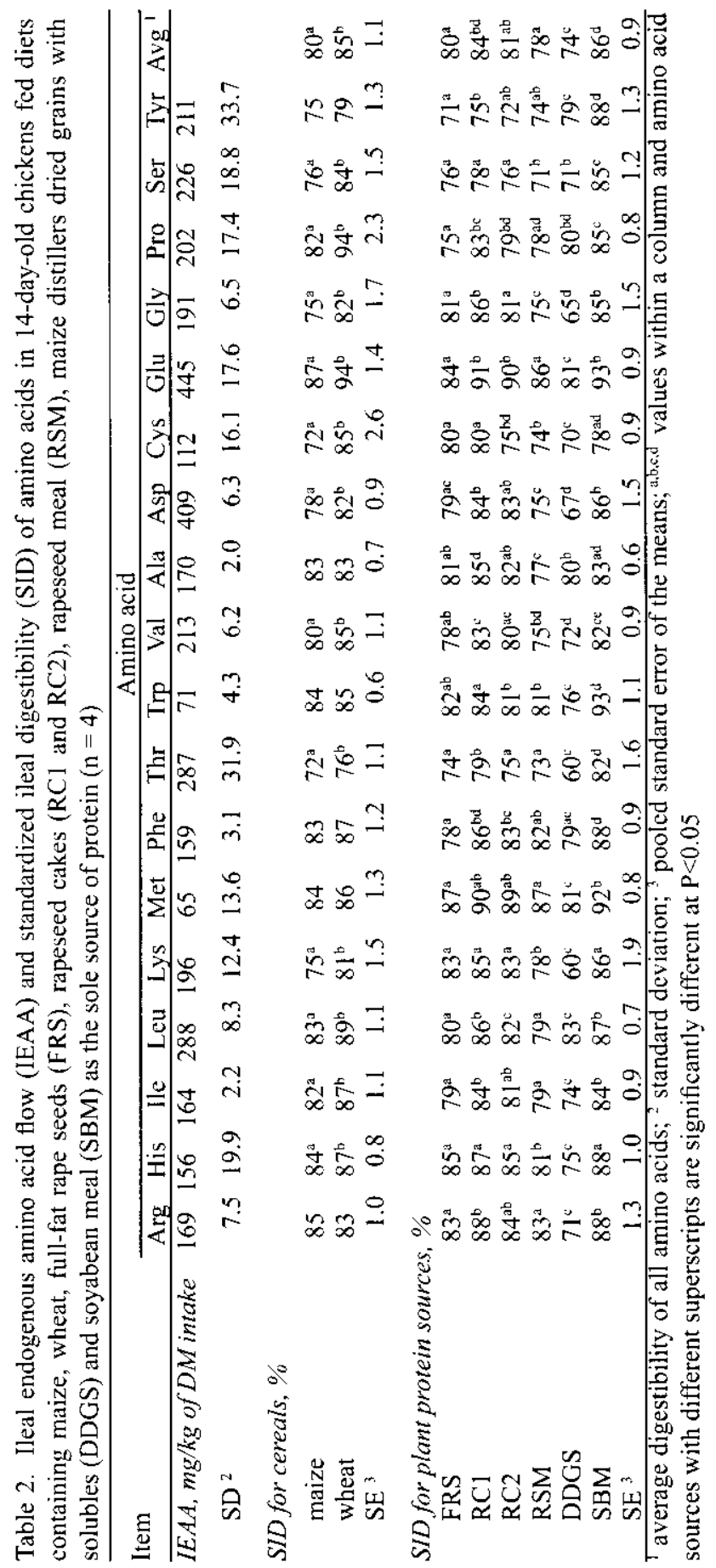


Of the four examined rapeseed feeds, RSM had the lowest $(\mathrm{P}<0.05)$ digestibility of Lys, His, Ala, Gly and Ser. Also the SID value for cystine in RSM was significantly lower than those in cold-pressed cake $\mathrm{RCl}$ and full-fat rape sceds. This supports the hypothesis that desolventizing/toasting process is the main factor responsible for the reduction in AA digestibility in conventional rapeseed meal in comparison with native seeds or non-toasted by-products (Perttilä et al., 2002; Newkirk et al., 2003). Interestingly, the SID coefficients of some essential AA in the cake RCI were very close to the respective values determined for SBM. These results agree with previous observations with 4- and 5-weck-old chickens (Perttilä et al., 2002; Szczurek, 2009) showing that the ileal digestibilities of Met, His, Arg, Leu, Phe and $\mathrm{Val}$ in rapeseed cakes produced using moderate temperatures are comparable $(\mathrm{P}>0.05)$ with those in soyabean meal.

Among protein sources under consideration DDGS had the lowest $(P<0.05)$ digestibility of the most limiting AA, Lys, Met, Thr, Trp and Cys (Table 2). The SID of some dispensable AA in DDGS were also at very low rates (e.g., Asp, Gly). The impaired digestibility of AA in maize DDGS is mainly related to the excessive heating during drying procedures, which may have resulted in the darker colour of the DDGS (Pahm et al., 2009). Adedokun et al. (2008), determined the digestibility of AA in two different maize DDGS samples and found in 3-week-old broilers the SID of all essential AA in dark DDGS to be considerably lower compared with light-coloured DDGS. In the current experiment the SID values for Lys, Met, Cys, Thr, Ile, Leu, and the average representing $18 \mathrm{AA}$, were generally similar to those obtained by the authors cited above for dark DDGS using the PFD method of standardization.

Overall, based on the standardized coefficients as indices of the ability of chickens at 14 days of life to digest the AA, the ingredients tested in this study can be ranked as follows. Within cereals: wheat $>$ maize; within protein-rich feeds: soyabean meal $>$ cold-pressed rapeseed cake $>$ rapeseed cake from cooked seeds $>$ full-fat rape seeds $>$ solvent-extracted rapeseed meal $>$ maize distillers dried grains with solubles.

Due to the methodological differences in terms of bird age and corrections of digestibility estimates for IEAA losses it is difficult to directly compare the present results with literature data. It is noteworthy, however, that the current SID estimates for AA in such ingredients as maize, rapeseed meal and soyabean meal are notably lower than those proposed by Lemme et al. (2004) in a set of standardized values (EHC method) generated with 42-day-old broilers. Interestingly, the AA digestibilities reported herein for DDGS, RSM and maize are also lower when compared with ileal digestibility data obtained in the previous experiment performed in our laboratory with birds at 30 days of life (Szczurek, 2009). Taking into account a strong methodological similarity between both studies, and the fact 
that in both experiments by-product samples from the same origin (producers) were used, these differences can likely be attributed to the age of birds. This suggests that age-associated effects should be considered for obtaining reliable information on AA digestibility in these ingredients for broiler chickens.

\section{ACKNOWLEDGEMENTS}

The able technical assistance of Mrs. Anna Arczewska is gratefully acknowledged.

\section{REFERENCES}

Adedokun S.A., Adeola O., Parsons C.M., Lilburn M.S., Applegate T.J., 2008. Standardized ileal amino acid digestibility of plant feedstuffs in broiler chickens and turkey poults using a nitrogenfree or casein diet. Poultry Sci. 87, 2535-2548

Adedokun S.A., Parsons C.M., Lilburn M.S., Adeola O., Applegate T.J., 2007. Comparison of ileal endogenous amino acid flows in broiler chicks and turkey poults. Poultry Sci. 86, 1682-1689

AOAC, 2000. Association of Official Analytical Chemists, Official Methods of Analysis. $17^{\text {th }}$ Edition. Gaithersburg, MD

Garcia A.R., Batal A.B., Dale N.M., 2007. A comparison of methods to determine amino acid digestibility of feed ingredients for chickens. Poultry Sci. 86, 94-101

Huang K.H., Ravindran V., Li X., Bryden W.L., 2005. Influence of age on the apparent ileal amino acid digestibility of feed ingredient for broiler chickens. Brit. Poultry Sci. 46, 236-245

Kadim 1.T., Moughan P.J., 1997. Development of an ileal amino acid digestibility assay for the growing chicken - effects of time after fecding and site of sampling. Brit. Poultry Sci. 38, 8995

Kadim I.T., Moughan P.J., Ravindran V., 2002. Ileal amino acid digestibility assay for the growing meat chicken - comparison of ileal and excreta amino acid digestibility in the chicken. Brit. Poultry Sci. 44, 588-597

Kluth H., Mehlhorn K., Rodehutscord M., 2005. Studies on the intestine section to be sampled in broiler studies on precaccal amino acid digestibility. Arch. Anim. Nutr. 59, 271-279

Lemme A., Ravindran V., Bryden W.L., 2004. lleal digestibility of amino acids in feed ingredients for broilers. World Poultry Sci. J. 60, 423-437

Moughan P.J., Schuttert G., Leenaars M., 1992. Endogenous amino acid flow in the stomach and small intestine of the young growing rat. J. Sci. Food Agr. 60, 437-442

Newkirk R.W., Classen H.L., Scott T.A., Edney M.J., 2003. The digestibility and content of amino acids in toasted and non-toasted canola meals. Can. J. Anim. Sci. 83, 131-139

Pahm A.A., Scherer C.S., Pettigrew J.E., Baker D.H., Parsons C.M., Stein H.H., 2009. Standardized amino acid digestibility in cecectomized roosters and lysine bioavailability in chicks fed distillers dricd grains with solubles. Poultry Sci. 88, 571-578

Perttilä S., Valaja J., Partanen K., Jalava T., Vanäläinen E., 2002. Apparent ileal digestibility of amino acids in protein feedstuffs and diet formulation based on total vs digestible lysine for poultry. Anim. Feed Sci. Tech. 98, 203-218 
Ravindran V., Hew L.I., Ravindran G., Bryden W.L., 2004. Endogenous amino acid flow in the avian ileum: quantification using three techniques. Brit. Poultry Sci. 92, 217-223

Ravindran V., Hew L.I., Ravindran G., Bryden W.L., 2005. Apparent ileal digestibility of amino acids in dietary ingredients for broiler chickens. Anim. Sci. 81, 85-97

Saha D.C., Gilbreath R.L., 1991. Analytical recovery of chromium from diet and feces determined by colorimetry and atomic absorption spectrophotometry. J. Sci. Food Agr. 55, 433-446

Smulikowska S., Rutkowski A. (Editors), 2005. Nutritional Recommendations and Feed Composition Tables for Poultry (in Polish). Publishers: The Kielanowski Institute of Animal Physiology and Nutrition, Polish Academy of Sciences, Jablonna (Poland) and Polish Branch of WPSA, pp. 105-109

Szczurek W., 2009. Standardized ileal digestibility of amino acids from several cereal grains and protein-rich feedstuffs in broiler chickens at the age of 30 days. J. Anim. Feed Sci. 18, 662-676 